Article

\title{
Essential Oil-Based Nano-Biopesticides: Formulation and Bioactivity against the Confused Flour Beetle Tribolium confusum
}

\author{
Davide Palermo, Giulia Giunti *(D), Francesca Laudani (D), Vincenzo Palmeri and Orlando Campolo ${ }^{(D)}$ \\ Department of Agriculture, University Mediterranea of Reggio Calabria, 89122 Reggio Calabria, Italy; \\ davide.palermo@unirc.it (D.P.); francesca.laudani@unirc.it (F.L.); vpalmeri@unirc.it (V.P.); \\ orlando.campolo@unirc.it (O.C.) \\ * Correspondence: giulia.giunti@unirc.it
}

check for updates

Citation: Palermo, D.; Giunti, G.; Laudani, F.; Palmeri, V.; Campolo, O. Essential Oil-Based

Nano-Biopesticides: Formulation and Bioactivity against the Confused Flour Beetle Tribolium confusum. Sustainability 2021, 13, 9746. https:// doi.org/10.3390/su13179746

Academic Editors: Salvatore Guarino and Ezio Peri

Received: 28 July 2021

Accepted: 25 August 2021

Published: 30 August 2021

Publisher's Note: MDPI stays neutral with regard to jurisdictional claims in published maps and institutional affiliations.

Copyright: (C) 2021 by the authors. Licensee MDPI, Basel, Switzerland. This article is an open access article distributed under the terms and conditions of the Creative Commons Attribution (CC BY) license (https:/ / creativecommons.org/licenses/by/ $4.0 /)$.
Abstract: Post-harvest pest control can rely on few approved pesticides and tools; hence, there is a rising interest in new sustainable, eco-friendly approaches. In this study, eight commercial essential oils (EOs) (anise Pimpinella anisum, artemisia Artemisia vulgaris, fennel Foenicum vulgare, garlic Allium sativum, lavender Lavandula angustifolia, mint Mentha piperita, rosemary Rosmarinus officinalis, and sage Salvia officinalis) were selected for their bioactivity and commercial availability, and then formulated in nano-emulsions. Repellency and acute toxicity of the developed nano-formulations were tested against a key stored product pest, Tribolium confusum (Coleoptera: Tenebrionidae). All the developed nano-emulsions presented optimal physical characteristics (droplet dimension = 95.01-144.30 nm; PDI = 0.146-0.248). All the formulations were repellent over time tested against adult beetles, in area preference bioassays. The best repellent was the anise EO-based formulation $\left(\mathrm{RC}_{50}=0.033 \mathrm{mg}\right)$. Mortality values from cold aerosol trials showed that the majority of tested EOs caused immediate acute toxicity, and garlic EO nano-emulsion caused the highest mortality of $T$. confusum adults $\left(\mathrm{LC}_{50}=0.486 \mathrm{mg} / \mathrm{L}\right.$ of air). EO-based nano-insecticides, used as cold aerosol and gel, are promising control methods against stored product pests, which can be integrated and combined with other sustainable biorational approaches.

Keywords: gel formulation; repellency; toxicity; nano-emulsions; insecticide; stored product pests; cold aerosol

\section{Introduction}

In the last decades, the global research effort has been aimed at the development of novel techniques of protection against agricultural, storage, and urban pests, and particularly at the increase of botanical substances and nontoxic materials. Food industry relies on limited effective control tools and authorized pesticides for stored pest control, increasing the interest of the scientific community to investigate and propose eco-friendly formulations and novel application techniques [1]. In the last century, the uncontrolled and irresponsible use of synthetic pesticides posed several environmental, ecological, and ecotoxicological problems [2]. Apart from the frequent insurgence of resistance in some pests and the consequent decrease of pesticide efficacy, synthetic insecticides can accumulate and contaminate the water, soil, and air, contaminating the whole food chain, including humans [3,4]. Furthermore, a decline and decrease of ecological diversity, including beneficial and non-target organisms and insects, such as pollinators, predators, and pest parasitoids, may be linked to the inappropriate and large application of synthetic pesticides [5].

Fumigants, such as methyl bromide and phosphine, have been primarily used against stored product insect pests because they are very effective against pests, but the ban of methyl bromide [6] and the growing resistance to phosphine [7] have determined the urgent development of alternative insecticides and fumigants for stored product pest management. 
Nanotechnologies are an emergent research area which can be applied for crop protection and be used to design novel active ingredients (a.i., hereafter) at nanoscale dimensions, generally termed "nano-pesticides" [8,9]. Nano-pesticides should possess certain key features to overcome the limitations and/or improve the bioactivity of synthetic and botanical insecticides, thus promoting stability and persistence in the environment, improving the toxicity toward target pests but avoiding secondary effects on non-target organisms or phytotoxicity, and affecting several different sites of actions [10]. Nowadays, the majority of the registered pesticides are neurotoxic, interfering directly with the insect nervous system; this kind of insecticide may pose risks also on mammals and non-target insects including pollinators, and therefore the formulation of nano-biopesticides with a different mode of action are required to improve the sustainability and safety of pest control [11].

Numerous biopesticides rely on plant extracts and secondary metabolites which, evolutionarily, are believed to be involved in plant protection against biotic and abiotic stress [12,13]. Among secondary metabolites, alkaloids, phenols, and terpenoids compounds are the most common ones [14]. These substances can be extracted by the plant tissues though solvent or steam distillation, obtaining a complex mixture of various molecules known as "essential oil" (EO, hereafter). Many EOs are bioactive substances with insecticidal activity against target pest species, including toxicant and repellent effects, developmental and behavioral alterations, and sterility/infertility [15]. EOs are traditional and ancient pest control tools; several millennia ago, around $2000 \mathrm{BC}$, botanicals were used in Asia, the Middle East, and Northern Africa to control stored grain pests [16]. The interest about the use of EOs as a control tool is linked to their low toxicity towards mammals, so that these substances are used as food protectives not only against insects $[17,18]$.

Despite their promising and well-recognized insecticidal activity, there are few commercial EO-based biopesticides due to some critical characteristics. EOs are highly volatile lipophilic substances, with rapid degradation and limited water solubility [19]. Furthermore, similarly to any plant extract, standardization of a.i. of EOs are critical, because their chemical composition depends on plant variety, season, and climatic conditions [20,21]. In this context, nanotechnologies may be useful to overcome some of these limitations; the inclusion of EOs inside nanoparticles or nano-emulsions can increase their stability, persistence, and water dispersibility [22,23].

This research aimed to formulate EO nano-emulsions from eight commercial standardized EOs. Nano-emulsions (droplet size: 100-300 nm) are kinetically stable oil-in-water $(\mathrm{O} / \mathrm{W})$ dispersions [24]. A lower surfactant concentration should be required to produce nano-emulsions rather than micro-emulsions [25]; thus, a high EO:surfactant ratio and percent amount of EO were used. Tested EOs were chosen based on preliminary surveys taking also into account their availability at reasonable costs, as well as based on their recognized insecticidal activity against other stored product pests [26]. After formulation, the insecticidal activity of these nano-emulsions was evaluated against economically important pests of stored grains, the confused flour beetle, Tribolium confusum du Val (Coleoptera: Tenebrionidae). This beetle is a cosmopolitan external feeder, which preferentially forages on flours and processed cereals, preferring previous infested or mechanically damaged kernels. Both T. confusum larvae and adults can cause post-harvest losses of several stored products, including wheat, maize, barley, sorghum, and other cereals [27]. The objective of this study was firstly to evaluate the repellent activity of gel dispenser produced from EO-based nano-emulsions toward T. confusum adults in area-preference trials. Next, the acute toxicity of cold aerosol fog treatment using the EO nano-formulations was assessed against adult beetles. Results from laboratory trials demonstrated the excellent physical quality of EO-based nano-emulsions and their promising insecticidal activity against the target pest species. 


\section{Materials and Methods}

\subsection{Insect Colonies and Rearing}

Tribolium confusum was reared at the laboratories of the Department of Agriculture of the University of Reggio Calabria for several generations. The original colony was obtained from infested organic wheat provided by a local milling plant (Melito Porto Salvo, RC; GPS coordinates: 37_55027.8" N, 15_45035.5" E). The insects were maintained in glass containers $(5 \mathrm{~L})$ and fed with commercial organic wheat flour mixed with brewer's yeast $(10: 1, w / w)$. Insect rearing was maintained under controlled thermo-hygrometric conditions $\left(25 \pm 1^{\circ} \mathrm{C}\right.$, $70 \pm 5 \% \mathrm{RH})$ with a photoperiod of $16 \mathrm{~h}: 8 \mathrm{~h}(\mathrm{~L}: \mathrm{D})$.

Tribolium confusum adults for trials were obtained by coetaneous cohorts, produced placing about 100 unsexed adult specimens inside $5 \mathrm{~L}$ glass jars containing $500 \mathrm{~g}$ of the above-described rearing medium; to ensure the absence of prior pest infestations, the diet was previously frozen for $72 \mathrm{~h}$ at $-20^{\circ} \mathrm{C}$. After 2 days, $T$. confusum adults were removed using a sieve, and the rearing medium was maintained under the same controlled conditions of rearing until adult progeny emergence. Newly emerged adults ( $2-8$ days old) were then used in the trials. Insects were collected from cultures using a $450 \mu \mathrm{m}$ sieve (Technotest; Modena, Italy) and a mouth aspirator.

\subsection{Essential Oils and Chemicals}

Commercial EOs of anise (Pimpinella anisum (Apiaceae)), artemisia (Artemisia vulgaris (Asteraceae)), fennel (Foenicum vulgare (Apiaceae)), garlic (Allium sativum (Amaryllidaceae)), lavender (Lavandula angustifolia (Lamiaceae)), mint (Mentha piperita (Lamiaceae)), rosemary (Rosmarinus officinalis (Lamiaceae)), and sage (Salvia officinalis (Lamiaceae)) were obtained from Esperis S.p.A. (Milan, Italy).

Hexane (95\%), Tween $80^{\circledR}$ (Polyoxyethylene (20) sorbitan monooleate), agarose, and sodium polyacrylatewere purchased from Sigma Aldrich (Munich, Germany).

\subsection{GC-MS Characterization of Essential Oils}

A Thermo Fisher TRACE 1300 gas chromatograph equipped with a MEGA-5 capillary column $(30 \mathrm{~m} \times 0.25 \mathrm{~mm}$; coating thickness $=0.25 \mu \mathrm{m})$ was used for GC-MS analyses (injection $=0.2 \mu \mathrm{L}$ of $10 \% \mathrm{EO} /$ hexane solution; split ratio $=1: 30$, injector and transfer line $\mathrm{T}=250$ and $240{ }^{\circ} \mathrm{C}$, respectively; oven $\mathrm{T}$ program $=$ from 60 to $240{ }^{\circ} \mathrm{C}$ at $3{ }^{\circ} \mathrm{C} / \mathrm{min}$; carrier gas $=$ helium, $1 \mathrm{~mL} / \mathrm{min}$ ). A Thermo Fisher ISQ LT ion-trap mass detector was used (scan time $=1.00 \mathrm{~s}$; prescan ionization time $=100 \mu \mathrm{s}$; scanned mass range $=30-300 \mathrm{~m} / \mathrm{z}$; ionization mode $=\mathrm{EI}$; emission current $=10$ microamps; count threshold $=1$ count; multiplier offset $=0 \mathrm{~V}$ ).

EO constituents were identified comparing their retention times (RT) and their linear retention indices (LRI) with those of standards, commercial libraries (NIST 05, Wiley FFNSC and ADAMS), and MS literature [28-32], and on spectra similarities with those of pure substances and known mixtures. LRI was calculated [33] using the retention times from a standard mixture of alkanes (C7-C30 saturated alkanes standard mixture, Supelco ${ }^{\circledR}$, Bellefonte, PA, USA), obtained at identical analytical conditions used for the EOs.

\subsection{Nano-Emulsion Formulation and Characterization}

The EO-based nano-emulsions were prepared following the method described by Giunti et al. [34]. Briefly, when a hydrophobic and an aqueous phase are mixed, a spontaneous emulsification process occurs, producing the coarse nano-emulsions. Each EO was firstly mixed with Tween $80(3: 1 \mathrm{w} / \mathrm{w})$ and stirred for $30 \mathrm{~min}$. Then, double-distilled water was added to this mix ( $4: 1 w / w$, respectively) and stirred for $60 \mathrm{~min}$, producing a coarse emulsion which underwent sonication by an UP200ST ultrasonic immersion homogenizer (Hielsher@, Teltow, Germany) at $100 \mathrm{~W}$ for $5 \mathrm{~min}$. The developed nano-emulsions contained $5 \%$ Tween $80,15 \%$ EO, and $80 \%$ water.

To evaluate the physical features of the developed formulations, the droplet surface charge, indicated by the zeta potential $(\zeta)$ values, and the droplet dimension, expressed in 
terms of Z-average size and polydispersity index (PDI), were determined using a Dynamic Light Scattering (DLS) instrument (Zetasizer Nano, Malvern). Each nano-emulsion was eluted in bi-distilled water $(1: 200 \mathrm{v} / \mathrm{v})$, and $1 \mathrm{~mL}$ and $0.75 \mathrm{~mL}$ of this solution were used for dimension and charge analyses, respectively. For each sample, three replicates (12-17 cycles each) were provided.

\subsection{Formulating Gels from EO Nano-Emulsions}

To produce the EO-based gels, a simple hydrophilic gel substrate was created; briefly, agarose provided a stronger texture and sodium polyacrylate maintained the gel hydration. A mixture of distilled water and agarose $(0.8 \% w / w)$ was heated, under constant agitation, until the complete melting of the agarose. When the mixture was completely melted, the EO-based nano-formulations (variable final concentrations from $80 \%$ to $0.005 \% w / w$ ) were added, concurrently with sodium polyacrylate $(0.4 \% w / w)$, and then the obtained mixture was stirred for $30 \mathrm{~s}$. Then, to avoid EO degradation caused by heating, the sodium polyacrylate mixture was immediately cooled in an ice-bath.

\subsection{Repellent Activity of EO Based Gels}

The repellent activity of EO-based gels was evaluated in area-preference bioassays [34]. Tested insects were placed inside a rectangular plexiglass box (length $\times$ width: $26.6 \mathrm{~cm} \times$ $15.6 \mathrm{~cm}$, height: $4.5 \mathrm{~cm}$ ), whose bottoms were covered with filter paper (Whatman $\mathrm{n}^{\circ} 1$ ), to facilitate T. confusum locomotion. Five $g$ of flour were used as food bait and placed on the opposite sides of the arena. Then, one of the two food baits was supplemented with $1 \mathrm{~g}$ of EO-based gel, while in the other a control gel containing a 5\% (w/w) Tween 80 water solution was added.

Several serial dilutions were used to produce every EO-based gel, depending on the different repellency of the various EOs, to obtain a sufficient number (at least 5) of concentrations suitable for statistical analysis. The tested dosages of EOs in the gels were:

- $\quad$ Anise EO, 15 dosages (120, 60, 30, 15, 7.5, 3.75, 1.875, 0.938, 0.469, 0.235, 0.117, 0.059, $0.029,0.015$ and $0.007 \mathrm{mg}$ of $\mathrm{EO})$

- $\quad$ Artemisia EO, 9 dosages $(120,60,30,15,7.5,3.75,1.875,0.938$ and $0.469 \mathrm{mg}$ of EO)

- $\quad$ Fennel EO, 12 dosages $(120,60,30,15,7.5,3.75,1.875,0.938,0.469,0.235,0.117$ and $0.059 \mathrm{mg}$ of $\mathrm{EO}$ )

- $\quad$ Garlic EO, 10 dosages $(7.5,3.75,1.875,0.938,0.469,0.235,0.117,0.059,0.029$ and $0.015 \mathrm{mg}$ of $\mathrm{EO})$

- $\quad$ Lavender EO, 6 dosages (120, 60, 30, 15, 7.5 and $3.75 \mathrm{mg}$ of EO)

- $\quad$ Mint EO, 9 dosages $(120,60,30,15,7.5,3.75,1.875,0.938$ and 0.469 mg of EO)

- $\quad$ Rosemary EO, 10 dosages $(120,60,30,15,7.5,3.75,1.875,0.938,0.469$ and $0.235 \mathrm{mg}$ of $\mathrm{EO})$

- $\quad$ Sage EO, 10 dosages $(120,60,30,15,7.5,3.75,1.875,0.938,0.469$ and $0.235 \mathrm{mg}$ of EO)

Unsexed T. confusum adults (2-8 days old) were released in the center of the arena. Plexiglas boxes were closed with a fine nylon mesh to avoid the arena olfactory saturation and prevent insect escape. The arenas were kept at $25 \pm 1{ }^{\circ} \mathrm{C}, 50 \pm 5 \%$ R.H., and under constant light conditions for the entire duration of the experiments. For every EO*dosage combination, 3 replicates with $30 \mathrm{~T}$. confusum adults each were provided. Insects were used only once. The number of insects on the two halves of the arena (i.e., treated or not) was recorded after $24 \mathrm{~h}$ and $48 \mathrm{~h}$ of exposure. No insect death occurred during the trials. The percent repellency (PR) for every EO-based gel and for every exposure time was calculated by the formula: $\mathrm{PR}(\%)=[(\mathrm{Nc}-\mathrm{Nt}) /(\mathrm{Nc}+\mathrm{Nt})] \times 100(\mathrm{Nc}=$ number of insects in the control; $\mathrm{Nt}=$ number of insects in the treatment) [35].

\subsection{Acute Toxicity by Cold Aerosol Trials}

The toxicity of the EO nano-emulsions against unsexed mixed adults of T. confusum (2-8 days old) was evaluated by cold aerosol applications following the method of Giunti et al. [34]. Cold aerosol treatments were arranged to place T. confusum adults inside a 
Perspex cage (length $\times$ width $\times$ height: $30 \mathrm{~cm} \times 30 \mathrm{~cm} \times 30 \mathrm{~cm})$, with a hole $(14 \mathrm{~mm} \varnothing)$ in one side at $15 \mathrm{~cm}$ height from the base; in this hole, an aerosol borosilicate-glass ampule (GammaDis Farmaceutici s.a.s., Civitanova Marche, Italy) can be hermetically inserted, and which received a constant flow of purified air $(2 \mathrm{~L} / \mathrm{min})$. Four $\mathrm{mL}$ of treatment solutions containing different concentrations of the EO nano-emulsion were poured into the ampule to produce the aerosol, and the airflow was turned off when the ampule was almost empty (i.e., residues $<0.1 \mathrm{~mL}$ ). The tested T. confusum were left inside the treated cage for $24 \mathrm{~h}$ of exposure; then, specimens were transferred in a clean, glass Petri dish containing the rearing medium. The mortality was recorded after $24 \mathrm{~h}$ and 1 week from the beginning of the cold aerosol treatment to account also for delayed mortality caused by the aerosol application. Trials were carried out at $25 \pm 1{ }^{\circ} \mathrm{C}, 50 \pm 5 \%$ R.H. with a photoperiod of $16 \mathrm{~h}: 8 \mathrm{~h}$ (L:D).

Several serial dilutions were tested for every EO-based nano-emulsion, depending on the different toxicity of the various EOs. The EO doses applied were:

- $\quad$ Anise EO, 6 doses $(22.22,11.11,5.56,2.78,1.39$ and $0.69 \mathrm{mg}$ of EO/L of air)

- $\quad$ Artemisia EO, 6 doses $(22.22,11.11,5.56,2.78,1.39$ and $0.69 \mathrm{mg} \mathrm{EO} / \mathrm{L}$ of air)

- $\quad$ Fennel EO, 5 doses (22.22, 11.11, 5.56, 2.78 and $1.39 \mathrm{mg}$ EO/L of air)

- $\quad$ Garlic EO, 8 doses $(22.22,11.11,5.56,2.78,1.39,0.69,0.35$ and $0.17 \mathrm{mg} \mathrm{EO} / \mathrm{L}$ of air)

- $\quad$ Lavender EO, 7 doses $(22.22,11.11,5.56,2.78,1.39,0.69$ and $0.35 \mathrm{mg}$ EO/L of air)

- $\quad$ Mint EO, 5 doses $(22.22,11.11,5.56,2.78$ and $1.39 \mathrm{mg} / \mathrm{L} \mathrm{mg} \mathrm{EO/L} \mathrm{in} \mathrm{air)}$

- $\quad$ Rosemary EO, 7 doses (22.22, 11.11, 5.56, 2.78, 1.39, 0.69 and $0.35 \mathrm{mg}$ EO/L of air)

- $\quad$ Sage EO, 5 doses $(22.22,11.11,5.56,2.78$ and $1.39 \mathrm{mg}$ EO/L of air)

Control trials were carried out using Tween 80 water solutions at the same concentrations tested in the EO nano-emulsions. Additional control trials using just double-distilled water were performed. Four replications of 20 unsexed T. confusum adults were provided for every EO dose.

\subsection{Data Analysis}

Statistical analyses were conducted with the software: IMB SPSS statistic 23 and Microsoft Excel ${ }^{\circledR}$.

PR data, calculated after $24 \mathrm{~h}$ and $48 \mathrm{~h}$ in area preference assays, were used to calculate the median repellent concentration $\left(\mathrm{RC}_{50}\right)$ of the tested EO-based gels with probit analysis.

In cold aerosol trials, the mortality was corrected for control mortality using Abbott's formula [36]; then, probit analysis was used to estimate the median lethal concentration $\left(\mathrm{LC}_{50}\right)$ at $24 \mathrm{~h}$ and $1 \mathrm{w}$ from exposure.

Both RC and LC values were considered significantly different when their respective 95\% fiducial limits (FL) did not overlap. Pearson's Goodness of Fit test was also used to ensure the suitability of probit analysis for these datasets.

\section{Results}

\subsection{Chemical Composition of Essential Oils}

EO constituents identified from GC-MS analyses are listed in Supplementary Table S1. Every EO presented a characteristic profile and different chemical composition.

The anise EO (32 identified compounds) was almost entirely composed of $(E)$-anethole (87.11\%) followed by estragol (3.98\%), foeniculin (2.01\%), and linalool (1.94\%). Similarly, the phenylpropanoids $(E)$-anethole $(42.13 \%)$ and estragol $(2.10 \%)$ were the major components of the fennel EO (26 identified compounds), followed by monoterpenes, like limonene $(32.96 \%)$, and fenchone $(7.67 \%)$.

The artemisia EO (33 identified compounds) was principally composed by oxygenated monoterpene $(84.52 \%)$, and the main constituents were $\alpha$-thujone $(28.42 \%)$, camphor $(22.21 \%), \beta$-thujone $(13.35 \%)$, chrysanthenone $(5.97 \%)$, and chrysantenyl acetate $(4.97 \%)$. Similar to artemisia, lavender $(87.88 \%)$, mint $(80.65 \%)$, rosemary $(68.52 \%)$, and sage $(58.64 \%)$ EOs were predominantly composed by oxygenated monoterpenes. The main constituents of the lavender EO (41 compounds identified) were linalool $(38.12 \%)$, linalyl 
acetate (36.31\%), camphor (7.01\%), and eucalyptol (5.01\%), while mint EO (31 identified compounds) contained (-)-menthol (37.67\%), menthone (22.10\%), isomenthone (8.75\%), limonene $(7.73 \%)$, and (-)-neomenthol (6.32\%). The rosemary EO (28 chemical constituents) was mainly composed by eucalyptol $(52.72 \%)$, followed by camphor $(12.04 \%), \alpha$-pinene $(11.28 \%)$, ortho-cymene $(4.01 \%)$, and $\beta$-pinene $(4.01 \%)$, whereas the sage EO (23 identified compounds) by $\alpha$-pinene (21.20\%), eucalyptol $(20.07 \%), \alpha$-thujone $(16.23 \%)$, camphor $(12.85 \%)$, and camphene (4.67\%).

In contrast, the garlic EO (72 identified compounds) was primarily composed by sulphur compounds $(99.8 \%)$, like diallyl disulfide $(30.09 \%)$, diallyl trisulfide $(22.70 \%)$, diallyl tetrasulfide (13.17\%), and diallyl sulfide $(11.09 \%)$.

\subsection{Characterization of EO-Based Nano-Emulsions}

All the developed nano-formulations presented an average droplet size within the nanoscale range $(95.01-144.3 \mathrm{~nm})$ and a low polydispersity index (0.146-0.248 PDI) (Supplementary Figure S1), which prove the excellent homogeneity of the nano-emulsions. The surface charge ( $\zeta$ Potential) of the droplets was always negative and ranged from -10.81 to $-23.8 \mathrm{mV}$ (Supplementary Figure S2). The physical characteristics of every developed nano-emulsion are reported in Table 1.

Table 1. Dynamic Light Scattering (DLS) analyses of EO-based nano-emulsions. Three replicates were provided for each EO.

\begin{tabular}{cccc}
\hline Essential Oil & $\begin{array}{c}\text { Z-Average Size } \pm \mathbf{S E}^{\mathbf{1}} \\
(\mathbf{n m})\end{array}$ & PDI $^{\mathbf{2}} \pm \mathbf{S E}$ & $\begin{array}{c}\zeta \text { potential } \pm \mathbf{S E} \\
(\mathbf{m V} \mathbf{)}\end{array}$ \\
\hline Anise & $128.23 \pm 0.37$ & $0.146 \pm 0.012$ & $-23.8 \pm 0.27$ \\
Artemisia & $95.01 \pm 0.03$ & $0.240 \pm 0.005$ & $-10.81 \pm 0.74$ \\
Fennel & $111.30 \pm 0.21$ & $0.154 \pm 0.005$ & $-16.50 \pm 0.35$ \\
Garlic & $144.30 \pm 0.15$ & $0.164 \pm 0.008$ & $-23.67 \pm 0.23$ \\
Lavender & $121.17 \pm 0.58$ & $0.172 \pm 0.005$ & $-11.60 \pm 0.06$ \\
Mint & $141.53 \pm 0.26$ & $0.189 \pm 0.009$ & $-18.40 \pm 0.76$ \\
Rosemary & $138.13 \pm 0.66$ & $0.248 \pm 0.004$ & $-22.30 \pm 0.21$ \\
Sage & $124.87 \pm 0.09$ & $0.181 \pm 0.006$ & $-13.27 \pm 0.20$ \\
\hline
\end{tabular}

${ }^{1} \mathrm{SE}=$ standard error $;{ }^{2} \mathrm{PDI}=$ Polydispersity index .

Among the analyzed EO-based nano-formulations, the artemisia EO nano-emulsion had the smallest average size of the droplets of $95.01 \pm 0.03$, whereas the polydispersity index $(0.240 \pm 0.005)$ was one of the highest recorded. In any case, no aggregates were detected (Supplementary Figure S2). In contrast, the highest droplet size was reported for the garlic EO-based nano-emulsion $(144.3 \pm 0.15 \mathrm{~nm})$, although the low PDI value highlighted the good homogeneity of the formulation.

\subsection{Repellent Activity of EO-Based Gel}

In area preference bioassays, repellency was noted for all the tested formulations. High EO concentrations caused saturation of the arena and hindered the orientation of the tested insects; thus, these concentrations were not used for probit analysis. No differences between the PR values recorded at $24 \mathrm{~h}$ and $48 \mathrm{~h}$ of exposure were noted within the same treatment (Table 2), suggesting that the repellent activity of the developed EO-based gels can last and remain stable over time tested. The probit analysis was performed for all the tested EOs and according to Pearson's test, PR values fitted the probit curve (Table 2). Regarding the EO nano-formulation used, the anise EO gel showed the highest repellency activity, while lavender one was the least effective against $T$. confusum adults. 
Table 2. Estimated median repellency concentrations $\left(\mathrm{RC}_{50}\right)$ of the various $\mathrm{EO}$ nano-formulations on T. confusum adults in the repellency bioassays. $\mathrm{RC}_{50}$ values were considered significantly different when their respective $95 \%$ fiducial limits did not overlap. Different letters within the same column indicate statistical differences $(p<0.05)$.

\begin{tabular}{|c|c|c|c|c|c|c|}
\hline EO & Time & $\begin{array}{c}\mathrm{RC}_{50}{ }^{1} \\
(\mathrm{mg} \text { of EO) }\end{array}$ & $95 \% \mathrm{FL}^{2}$ & $\begin{array}{l}\text { Slope } \\
\pm \mathrm{SE}^{3}\end{array}$ & $\begin{array}{c}\text { Pearson's } \chi^{2} \\
\left(\text { df }^{4}\right)\end{array}$ & $p$ \\
\hline \multirow{2}{*}{ Anise } & $24 \mathrm{~h}$ & $0.042 \mathrm{a}$ & $0.028-0.064$ & $1.25 \pm 0.11$ & $7.41(4)$ & 0.116 \\
\hline & $48 \mathrm{~h}$ & $0.033 \mathrm{a}$ & $0.024-0.043$ & $0.87 \pm 0.11$ & $5.51(4)$ & 0.239 \\
\hline \multirow{2}{*}{ Artemisia } & $24 \mathrm{~h}$ & $1.622 \mathrm{c}$ & $0.535-3.820$ & $0.98 \pm 0.14$ & 7.35 (3) & 0.068 \\
\hline & $48 \mathrm{~h}$ & $1.262 \mathrm{c}$ & $1.856-2.794$ & $-0.21 \pm 0.07$ & $2.40(3)$ & 0.495 \\
\hline \multirow{2}{*}{ Fennel } & $24 \mathrm{~h}$ & $0.158 b$ & $0.092-0.239$ & $1.48 \pm 0.15$ & $5.50(3)$ & 0.139 \\
\hline & $48 \mathrm{~h}$ & $0.177 \mathrm{~b}$ & $0.130-0.221$ & $1.47 \pm 0.21$ & $3.45(3)$ & 0.178 \\
\hline \multirow{2}{*}{ Garlic } & $24 \mathrm{~h}$ & $0.055 \mathrm{a}$ & $0.038-0.074$ & $0.79 \pm 0.11$ & $6.45(4)$ & 0.168 \\
\hline & $48 \mathrm{~h}$ & $0.095 \mathrm{ab}$ & $0.046-0.212$ & $0.70 \pm 0.10$ & $6.95(4)$ & 0.139 \\
\hline \multirow{2}{*}{ Lavender } & $24 \mathrm{~h}$ & $15.389 \mathrm{~d}$ & 11.729-19.683 & $0.99 \pm 0.11$ & $0.66(4)$ & 0.956 \\
\hline & $48 \mathrm{~h}$ & $19.625 \mathrm{~d}$ & $15.130-24.457$ & $1.23 \pm 0.15$ & $4.56(4)$ & 0.207 \\
\hline \multirow{2}{*}{ Mint } & $24 \mathrm{~h}$ & $1.083 \mathrm{bc}$ & $0.205-0.882$ & $0.66 \pm 0.14$ & $3.22(3)$ & 0.359 \\
\hline & $48 \mathrm{~h}$ & $1.601 \mathrm{c}$ & $0.387-1.215$ & $0.67 \pm 0.14$ & $4.52(3)$ & 0.211 \\
\hline \multirow{2}{*}{ Rosemary } & $24 \mathrm{~h}$ & $0.577 \mathrm{c}$ & $0.249-0.968$ & $1.27 \pm 0.15$ & $6.63(3)$ & 0.085 \\
\hline & $48 \mathrm{~h}$ & $0.816 \mathrm{c}$ & $0.435-1.397$ & $1.33 \pm 0.15$ & $6.80(3)$ & 0.078 \\
\hline \multirow{2}{*}{ Sage } & $24 \mathrm{~h}$ & $0.719 \mathrm{c}$ & $0.370-1.144$ & $1.14 \pm 0.11$ & $9.07(4)$ & 0.059 \\
\hline & $48 \mathrm{~h}$ & $1.985 \mathrm{c}$ & $1.263-3.510$ & $1.19 \pm 0.11$ & $9.26(4)$ & 0.055 \\
\hline
\end{tabular}

${ }^{1}$ Median repellent concentration; ${ }^{2}$ Fiducial limits; ${ }^{3}$ Standard error; ${ }^{4}$ degrees of freedom.

\subsection{Toxicity of EO-Based Nano-Emulsions}

Mortality values from cold aerosol trials fitted the probit curve for all the tested EOs (Table 3). Results showed that the majority of tested EOs can exert an immediate acute toxicity, which cannot cause delayed mortality in T. confusum. In contrast, for two EO-based nano-emulsions (i.e., artemisia and mint), the $\mathrm{LC}_{50}$ values after 1 week were significantly lower with respect to those reported just after $24 \mathrm{~h}$, as their $95 \%$ fiducial limits did not overlap (Table 3). Thus, for two EO nano-formulations, beside the immediate acute toxicity, additive toxicity can be noted, suggesting that delayed mortality induced by the nano-emulsion occurred. Summarizing, garlic EO nano-emulsion showed the highest toxic activity against $T$. confusum adults, whereas artemisia has the lowest one.

Table 3. Estimated median lethal concentrations $\left(\mathrm{LC}_{50}\right)$ of the various $\mathrm{EO}$ nano-formulations on $T$. confusum adults in the aerosol bioassays. $\mathrm{LC}_{50}$ values were considered significantly different when their respective $95 \%$ fiducial limits did not overlap. Different letters within the same column indicate statistical differences $(p<0.05)$.

\begin{tabular}{|c|c|c|c|c|c|c|}
\hline EO & Time & $\begin{array}{c}\mathrm{LC}_{50}{ }^{1} \\
\text { (mg/L of Air) }\end{array}$ & $95 \% \mathrm{FL}^{2}$ & $\begin{array}{l}\text { Slope } \\
\pm \mathrm{SE}^{3}\end{array}$ & $\begin{array}{c}\text { Pearson's } \chi^{2} \\
\left(\mathrm{df}^{4}\right)\end{array}$ & $p$ \\
\hline \multirow{2}{*}{ Anise } & $24 \mathrm{~h}$ & $2.561 \mathrm{~b}$ & $1.988-3.239$ & $2.28 \pm 0.16$ & $6.67(4)$ & 0.149 \\
\hline & $1 \mathrm{w}$ & $2.099 \mathrm{~b}$ & $1.833-2.385$ & $2.32 \pm 0.17$ & $5.96(4)$ & 0.202 \\
\hline \multirow{2}{*}{ Artemisia } & $24 \mathrm{~h}$ & $7.462 \mathrm{~d}$ & $6.058-9.496$ & $1.25 \pm 0.12$ & $5.62(4)$ & 0.229 \\
\hline & $1 \mathrm{w}$ & $4.069 \mathrm{c}$ & $3.370-4.924$ & $1.34 \pm 0.12$ & $2.35(4)$ & 0.671 \\
\hline \multirow{2}{*}{ Fennel } & $24 \mathrm{~h}$ & $3.764 \mathrm{bc}$ & $2.699-5.018$ & $2.42 \pm 0.19$ & $5.78(3)$ & 0.123 \\
\hline & $1 \mathrm{w}$ & $3.369 \mathrm{bc}$ & $2.323-4.561$ & $2.35 \pm 0.19$ & $6.12(3)$ & 0.106 \\
\hline \multirow{2}{*}{ Garlic } & $24 \mathrm{~h}$ & $0.486 \mathrm{a}$ & $0.381-0.601$ & $1.30 \pm 0.15$ & $2.48(3)$ & 0.478 \\
\hline & $1 \mathrm{w}$ & $0.325 \mathrm{a}$ & $0.243-0.408$ & $1.26 \pm 0.15$ & $0.15(3)$ & 0.986 \\
\hline \multirow{2}{*}{ Lavender } & $24 \mathrm{~h}$ & $4.476 \mathrm{bcd}$ & $3.039-7.061$ & $1.18 \pm 0.09$ & $10.98(5)$ & 0.052 \\
\hline & $1 \mathrm{w}$ & $2.048 \mathrm{~b}$ & $1.482-2.776$ & $1.36 \pm 0.10$ & $8.50(5)$ & 0.131 \\
\hline
\end{tabular}


Table 3. Cont.

\begin{tabular}{|c|c|c|c|c|c|c|}
\hline EO & Time & $\begin{array}{c}\mathrm{LC}_{50}{ }^{1} \\
\text { (mg/L of Air) }\end{array}$ & $95 \% \mathrm{FL}^{2}$ & $\begin{array}{l}\text { Slope } \\
\pm \mathrm{SE}^{3}\end{array}$ & $\begin{array}{c}\text { Pearson's } \chi^{2} \\
\left(\mathrm{df}^{4}\right)\end{array}$ & $p$ \\
\hline \multirow{2}{*}{ Mint } & $24 \mathrm{~h}$ & $3.768 \mathrm{c}$ & $3.298-4.275$ & $2.41 \pm 0.19$ & $2.41(3)$ & 0.492 \\
\hline & $1 \mathrm{w}$ & $2.915 \mathrm{~b}$ & $2.527-3.316$ & $2.47 \pm 0.21$ & $3.22(3)$ & 0.359 \\
\hline \multirow{2}{*}{ Rosemary } & $24 \mathrm{~h}$ & $6.098 \mathrm{~cd}$ & $4.666-8.651$ & $1.09 \pm 0.12$ & $5.70(4)$ & 0.222 \\
\hline & $1 \mathrm{w}$ & 4.582 c & $3.646-6.048$ & $1.18 \pm 0.12$ & $6.70(4)$ & 0.153 \\
\hline \multirow{2}{*}{ Sage } & $24 \mathrm{~h}$ & $5.782 \mathrm{c}$ & $5.146-6.506$ & $2.68 \pm 0.20$ & $4.42(3)$ & 0.219 \\
\hline & $1 \mathrm{w}$ & 4.119 c & $3.665-4.613$ & $2.82 \pm 0.21$ & $2.78(3)$ & 0.427 \\
\hline
\end{tabular}

${ }^{1}$ Median lethal concentration; ${ }^{2}$ Fiducial limits; ${ }^{3}$ Standard error; ${ }^{4}$ degrees of freedom.

\section{Discussion}

The qualitative traits of the developed nano-emulsions, as well as their biological activity, were mainly dependent on the plant-source and the EO chemical characteristics since every formulation presented distinctive traits. The good quality of all the developed nano-formulations was supported by the low PDI values (0.15-0.25), indicating a good homogeneity of the droplet size distribution. Among the nano-emulsions, the different average droplet dimensions can be related to the composition of EOs; indeed, artemisia EO, which produced the smallest droplet size, is mainly constituted of oxygenated monoterpenes, while the peculiar chemical composition of garlic EO, which formed the biggest micelles, is mainly based on organosulfur compounds. For instance, the molecular weight, polarity, and conformation of EO compounds, as well as on the presence of surface-active substances among the constituents, can influence the droplet formation process using Tween $80[37,38]$. Nevertheless, the physical characteristics of all nano-emulsions were excellent and congruent with the classification of "nanomaterials".

In the present study, EO-based nano-emulsions were developed using a mixed bottomup/top-down process aimed at the reduction of the amount of surfactant while increasing the $\mathrm{EO}$ rate (i.e., 15\%) [39]. Tweens derive from sorbitan esters, which are water-soluble nonionic compounds. Among non-ionic surfactants, Tween 80 is one of the most commonly used for EO-based formulations and it can produce optimal droplet dimensions when combined with sonication [40]. Hashem et al. [41] produced a P. anisum nano-emulsion $(\mathrm{EO}=14 \%, v / v$; ethanol $=3 \%, v / v$; Tween $80=3 \%, v / v)$ just through the self-emulsification process, obtaining a larger droplet size $(198.9 \mathrm{~nm})$ and higher PDI values $(0.303)$ compared with the anise EO-based formulation produced in this study. Furthermore, several recent studies demonstrated that the droplet size of nano-emulsions is reduced when the oil:surfactant ratio decreases and that a large amount of surfactant could ensure small dimensions [42,43], although the use of high amounts of surfactants could cause a negative effect on plants and food when nano-formulations are used as pesticides [44,45]. Here, the droplet dimensions of the developed nano-biopesticides were similar to those of EO-based nano-emulsions containing a lower oil:surfactant ratio [46,47].

The repellent activity of EO-based nano-emulsions and gels has been largely investigated for insect vector management [48-50], though they may also be exploited for stored product pest control [51]. The area-preference trials highlighted good repellent activity toward T. confusum of the majority of the developed gels. Except for lavender EO gel, the $\mathrm{RC}_{50}$ values calculated for the other gels were very low, compared also with results reported in literature for pure EOs [26]. Unfortunately, the calculation of $\mathrm{RD}_{50}$ values is not very common in literature, making the comparison of the repellency of different Eos difficult [26]. As an example, Pistacia lentiscus (Anacardiaceae) EO demonstrated a good repellent activity against $T$. confusum with $\mathrm{RD}_{50}=0.025 \mu \mathrm{L} / \mathrm{cm}^{2}$ after $24 \mathrm{~h}$ in areapreference bioassays in the Petri dish arena [52]; however, the comparison with our results is not simple, because the $\mathrm{RC}_{50}$ values refer to different experimental designs, since in our experiments the repellent was used to treat the "walking surface" and insects did not 
directly contact the repellent. The development of an EO gel releaser was indeed intended to simulate the treatment application in real operative conditions using dispensers.

Furthermore, this trial aimed at the repellency evaluation for longer durations. Usually, repellency of botanicals is assessed using the classic Petri dish arena for area preference and data are collected after just a few hours of exposure [26]. Indeed, EOs are very volatile, and their persistence is very low under this kind of condition. The formulation of EOs in nano-systems can alter the repellent efficacy of the raw extracts; as an example, $R$. dominica adults were repelled more by the pure EOs than by PEG-EO nanoparticles when used as antifeedants, while for T. confusum the PEG nano-formulation improved the deterrent activity of the EOs [23]. In fact, nano-dimensions generally enhance the gradual release of the active compounds [10], which, at low concentrations, may not be repellent for target species. For instance, gradual release can have some inconveniences; the release of constant low concentrations of EO active constituents can cause the insurgence of habituation [53] or can trigger attraction rather than repellency toward the target pest species $[54,55]$. Thus, these critical aspects turn the crucial point of EO dispenser formulations on the balance between EO preservation and its release. Nevertheless, the results described in the present study suggested that a long-lasting gel dispenser with an appropriate EO concentration can boost the efficacy of the a.i. over time.

In literature, EOs against foodstuff pests are commonly evaluated as fumigants or are directly administered on foodstuff [26]. However, these techniques are unfeasible in industry operative conditions. For a correct fumigation treatment using EOs as such, sealed airtight spaces would be necessary and the homogeneous distribution in large spaces would be quite limiting. On the other hand, the direct use of pure EOs on food may alter their sensorial and nutritional qualities. Conversely, the treatment of warehouses and buildings using the cold aerosol technique is quite common and easy to handle by the operators operating in the disinfection sector.

The developed nano-emulsions showed remarkable toxicity against T. confusum as a cold aerosol. This kind of application of the nano-emulsions can improve the efficacy of this treatment because cold aerosol operates as contact and fumigant insecticide. Previous research, on cold aerosol toxicity of sweet orange (Citrus sinensis) EO nano-emulsion against the same pest species, reported higher $\mathrm{LC}_{50}$ values $(5.43 \mathrm{mg} / \mathrm{mL}$ after $24 \mathrm{~h})$ compared with those recorded in the present study [34]; in detail, the garlic EO nano-emulsion was 10-fold more toxic against $T$. confusum adults compared with the citrus one. The EO nano-emulsions presented here had similar insecticidal activity against $T$. confusum compared to commercial fogging agents. As an example, pyrethrin aerosol (23.4 g formulation $/ 28 \mathrm{~m}^{3}$ of headspace area) after 7 days from exposure caused a lower than $40 \%$ mortality rate against $T$. confusum, but this increased to almost $85 \%$ after 14 days [56]. The strong toxicity demonstrated by the EO-based nano-formulations can also be attributed to their nanometric scale that increases the bioavailability and bioactivity of the active components [57]. However, the exact mode of action of EOs against this target species has not been clarified yet, although previous studies demonstrated that monoterpenes could interfere with the octopaminergic system of the pests, resulting in damages to the nervous system $[15,58]$. To the best of our knowledge, the mode of action of EO in T. confusum has just been investigated by Petrović et al. [59]; this study demonstrated that Carum carvi L. EO can alter the antioxidative defense system (i.e., catalase, superoxide dismutase, and glutathione-S-transferase), as well as the detoxification system (i.e., lipid peroxidation, reduced glutathione) [59].

From 1980, an impressive increase of research about botanical insecticides has been recorded [60]; however, the use of EOs for insect control still represents a niche compared with other applications and few authorized commercial EO-based insecticides are available. The tested EO-based nano-emulsions may be potential candidates for IPM in post-harvest since they were effective in controlling and repelling the target pest. Moreover, the production process for nano-emulsions is very similar to those of some commercial "next generation" synthetic insecticides, and thus their production is scalable by the pesticide industry. Similarly, aerosol and fogging systems are well recognized alternatives to fumi- 
gation already used for sanitation in confined spaces [61,62]. Nano-biopesticides, as cold aerosol and gel, can be useful to sanitize and disinfest both production areas and warehouses, as well as machinery and equipment. Furthermore, the proposed techniques can be used in combination with other sustainable control approaches to deter insect feeding, avoiding any kind of residues on food.

Future studies about the mechanisms of action of the EOs against insect pests are needed to clarify the target sites of different $\mathrm{EO}$ and to produce effective bio-insecticides. Indeed, knowledge on this aspect can highlight possible impacts toward non-target organisms. In addition, sensory analysis of food treated with these natural compounds is fundamental to improve consumer acceptance, although it has been often disregarded by the scientific community. Therefore, a multidisciplinary approach, also involving chemists and food technologists, should be the primary route to develop eco-friendly EO-based insecticides. Lastly, further research is needed to test the efficacy of the developed nanoinsecticides under more realistic operative conditions to evaluate their enforceability on a larger scale.

\section{Conclusions}

The EO-based nano-emulsions tested in this study presented optimal physical characteristics, although every EO had a different chemical profile. The bioactivity against the target pest, T. confusum, was assessed through repellency and toxicity trials, highlighting that the anise EO-based gel was the best repellent and the garlic nano-formulation, used as a cold aerosol, caused the highest mortality. The insecticidal activity of the developed nanoinsecticides can be considered promising for further applications in operative conditions.

Supplementary Materials: The following are available online at https:/ / www.mdpi.com/article/10 .3390/su13179746/s1, Supplementary Table S1: GC-MS analysis of the selected EOs, Supplementary Figure S1: Dimensional values of nano-emulsions containing anise(A), artemisia(B), fennel(C), garlic(D), lavender(E), $\operatorname{mint}(\mathbf{F})$, rosemary $(\mathbf{G})$ or sage $(\mathbf{H})$ EO, Supplementary Figure S2: $\zeta$ potential values of nano-emulsions containing anise(A), artemisia(B), fennel(C), garlic(D), lavender(E), $\operatorname{mint}(\mathbf{F})$, $\operatorname{rosemary}(\mathbf{G})$ or sage $(\mathbf{H}) \mathrm{EO}$.

Author Contributions: Conceptualization, D.P., G.G. and O.C.; methodology, D.P. and O.C.; validation, D.P. and F.L.; formal analysis, D.P., G.G. and O.C.; investigation, D.P. and G.G.; resources, F.L. and V.P.; data curation, D.P. and G.G.; writing—original draft preparation, D.P. and G.G.; writingreview and editing, F.L., V.P. and O.C.; visualization, D.P. and G.G.; supervision, V.P. and O.C.; project administration, V.P.; funding acquisition, V.P. and O.C. All authors have read and agreed to the published version of the manuscript.

Funding: This research received no external funding. G.G. was funded by Progetto Mipaaaf Bando Olio "Controllo ecosostenibile dei fitofagi dell'olivo-CEBIOL (CUP: C34Il 9000300005)", Grant ID: 1/2021/AGRARIA.

Institutional Review Board Statement: Not applicable.

Informed Consent Statement: Not applicable.

Data Availability Statement: The data that support the findings of this study are available from the corresponding author [G.G.] upon reasonable request.

Conflicts of Interest: The authors declare no conflict of interest. The funders had no role in the design of the study; in the collection, analyses, or interpretation of data; in the writing of the manuscript, or in the decision to publish the results.

\section{References}

1. Stejskal, V.; Vendl, T.; Aulicky, R.; Athanassiou, C. Synthetic and Natural Insecticides: Gas, Liquid, Gel and Solid Formulations for Stored-Product and Food-Industry Pest Control. Insects 2021, 12, 590. [CrossRef] [PubMed]

2. Lamichhane, J.R.; Dachbrodt-Saaydeh, S.; Kudsk, P.; Messéan, A. Toward a Reduced Reliance on Conventional Pesticides in European Agriculture. Plant Dis. 2015, 100, 10-24. [CrossRef] [PubMed] 
3. Benelli, G.; Pavela, R.; Maggi, F.; Petrelli, R.; Nicoletti, M. Commentary: Making Green Pesticides Greener? The Potential of Plant Products for Nanosynthesis and Pest Control. J. Clust. Sci. 2016, 28, 3-10. [CrossRef]

4. Tudi, M.; Ruan, H.D.; Wang, L.; Lyu, J.; Sadler, R.; Connell, D.; Chu, C.; Phung, D.T. Agriculture Development, Pesticide Application and Its Impact on the Environment. Int. J. Environ. Res. Public Health 2021, 18, 1112. [CrossRef]

5. Mancini, F.; Woodcock, B.A.; Isaac, N.J.B. Agrochemicals in the wild: Identifying links between pesticide use and declines of nontarget organisms. Curr. Opin. Environ. Sci. Health 2019, 11, 53-58. [CrossRef]

6. Fields, P.G.; White, N.D.G. Alternative to methyl bromide treatments for stored-product and quarantine insects. Annu. Rev. Entomol. 2002, 47, 331-359. [CrossRef]

7. Nayak, M.K.; Daglish, G.J. Importance of Stored Product Insects. In Recent Advances in Stored Product Protection; Athanassiou, C.G., Arthur, F.H., Eds.; Springer: Berlin/Heidelberg, Germany, 2018; pp. 1-17, ISBN 9783662561256.

8. Damalas, C.A.; Koutroubas, S.D. Current Status and Recent Developments in Biopesticide Use. Agriculture 2018, 8, 13. [CrossRef]

9. He, X.; Deng, H.; Hwang, H.M. The current application of nanotechnology in food and agriculture. J. Food Drug Anal. 2019, 27, 1-21. [CrossRef] [PubMed]

10. De Oliveira, J.L.; Campos, E.V.R.; Bakshi, M.; Abhilash, P.C.; Fraceto, L.F. Application of nanotechnology for the encapsulation of botanical insecticides for sustainable agriculture: Prospects and promises. Biotechnol. Adv. 2014, 32, 1550-1561. [CrossRef] [PubMed]

11. Athanassiou, C.G.; Kavallieratos, N.G.; Benelli, G.; Losic, D.; Usha Rani, P.; Desneux, N. Nanoparticles for pest control: Current status and future perspectives. J. Pest Sci. 2018, 91, 1-15. [CrossRef]

12. Zaynab, M.; Fatima, M.; Abbas, S.; Sharif, Y.; Umair, M.; Zafar, M.H.; Bahadar, K. Role of secondary metabolites in plant defense against pathogens. Microb. Pathog. 2018, 124, 198-202. [CrossRef] [PubMed]

13. Giunti, G.; Benelli, G.; Conte, G.; Mele, M.; Caruso, G.; Gucci, R.; Flamini, G.; Canale, A. VOCs-Mediated Location of Olive Fly Larvae by the Braconid Parasitoid Psyttalia concolor: A Multivariate Comparison among VOC Bouquets from Three Olive Cultivars. Biomed. Res. Int. 2016, 2016, 7827615. [CrossRef]

14. Mithöfer, A.; Boland, W. Plant Defense Against Herbivores: Chemical Aspects. Annu. Rev. Plant Biol. 2012, 63, 431-450. [CrossRef]

15. Isman, M.B. Plant essential oils for pest and disease management. Crop Prot. 2000, 19, 603-608. [CrossRef]

16. Kubeczka, K.-H. History and Sources of Essential Oil Research. In Handbook of Essential Oils; Başer, K.H.C., Buchbauer, G., Eds.; CRC Press: Boca Raton, FL, USA, 2020; pp. 3-39. ISBN 9781351246460.

17. Romeo, F.V.; De Luca, S.; Piscopo, A.; De Salvo, E.; Poiana, M. Effect of Some Essential Oils as Natural Food Preservatives on Commercial Grated Carrots. J. Essent. Oil Res. 2011, 22, 283-287. [CrossRef]

18. Jancikova, S.; Dani, D.; Petr, S.; Marcela, N.; Jakub, T.; Bohuslava, T. Edible films from carrageenan/orange essential oil/trehalosestructure, optical properties, and antimicrobial activity. Polymers 2021, 13, 1-19.

19. Moretti, M.D.L.; Sanna-Passino, G.; Demontis, S.; Bazzoni, E. Essential oil formulations useful as a new tool for insect pest control. AAPS PharmSciTech 2002, 3, 64-74. [CrossRef]

20. Fabroni, S.; Ruberto, G.; Rapisarda, P. Essential oil profiles of new Citrus hybrids, a tool for genetic citrus improvement. J. Essent. Oil Res. 2012, 24, 159-169. [CrossRef]

21. Thompson, J.D.; Chalchat, J.-C.; Michet, A.; Linhart, Y.B.; Ehlers, B. Qualitative and Quantitative Variation in Monoterpene Co-Occurrence and Composition in the Essential Oil of Thymus vulgaris Chemotypes. J. Chem. Ecol. 2003, 29, 859-880. [CrossRef]

22. Campolo, O.; Cherif, A.; Ricupero, M.; Siscaro, G.; Grissa-Lebdi, K.; Russo, A.; Cucci, L.M.; Di Pietro, P.; Satriano, C.; Desneux, N.; et al. Citrus peel essential oil nanoformulations to control the tomato borer, Tuta absoluta: Chemical properties and biological activity. Sci. Rep. 2017, 7, 13036. [CrossRef] [PubMed]

23. Werdin González, J.O.; Gutiérrez, M.M.; Ferrero, A.A.; Fernández Band, B. Essential oils nanoformulations for stored-product pest control-Characterization and biological properties. Chemosphere 2014, 100, 130-138. [CrossRef]

24. Tadros, T.; Izquierdo, P.; Esquena, J.; Solans, C. Formation and stability of nano-emulsions. Adv. Colloid Interface Sci. 2004, 108-109, 303-318. [CrossRef]

25. Golden, G.; Quinn, E.; Shaaya, E.; Kostyukovsky, M.; Poverenov, E. Coarse and nano emulsions for effective delivery of the natural pest control agent pulegone for stored grain protection. Pest Manag. Sci. 2018, 74, 820-827. [CrossRef] [PubMed]

26. Campolo, O.; Giunti, G.; Russo, A.; Palmeri, V.; Zappalà, L. Essential Oils in Stored Product Insect Pest Control. J. Food Qual. 2018, 2018, 1-18. [CrossRef]

27. Boyer, S.; Zhang, H.; Lempérière, G. A review of control methods and resistance mechanisms in stored-product insects. Bull. Entomol. Res. 2012, 102, 213-229. [CrossRef] [PubMed]

28. Adams, R.P. Identification of Essential Oil Components by Gas Chromatography/Mass Spectrometry; Allured Publishing Corporation: Carol Steam, IL, USA, 1995; ISBN 978-1-932633-21-4.

29. Davies, N.W. Gas chromatographic retention indices of monoterpenes and sesquiterpenes on methyl silicon and Carbowax 20M phases. J. Chromatogr. A 1990, 503, 1-24. [CrossRef]

30. Jennings, W. Qualitative Analysis of Flavor and Fragrance Volatiles by Glass Capillary Gas Chromatography; Academic Press: New York, NY, USA, 1980; ISBN 0323141056.

31. Masada, Y. Analysis of Essential Oils by Gas Chromatography and Mass Spectrometry; John Wiley and Sons, Inc.: New York, NY, USA, 1976. 
32. Stenhagen, E.; Abrahamsson, S.; McLafferty, F.W. Registry of Mass Spectral Data; John Wiley \& Sons, Ltd.: New York, NY, USA, 1974.

33. Van Den Dool, H.; Kratz, P.D. A generalization of the retention index system including linear temperature programmed gas-liquid partition chromatography. J. Chromatogr. 1963, 11, 463-471. [CrossRef]

34. Giunti, G.; Palermo, D.; Laudani, F.; Algeri, G.M.; Campolo, O.; Palmeri, V. Repellence and acute toxicity of a nano-emulsion of sweet orange essential oil toward two major stored grain insect pests. Ind. Crops Prod. 2019, 142, 111869. [CrossRef]

35. Mostafiz, M.M.; Shim, J.-K.; Hwang, H.-S.; Bunch, H.; Lee, K.-Y. Acaricidal effects of methyl benzoate against Tetranychus urticae Koch (Acari: Tetranychidae) on common crop plants. Pest Manag. Sci. 2020, 76, 2347-2354. [CrossRef]

36. Abbott, W.S. A method of computing the effectiveness of an insecticide. J. Am. Mosq. Control Assoc. 1925, 3, 302-303. [CrossRef]

37. Acevedo-Fani, A.; Salvia-Trujillo, L.; Rojas-Graü, M.A.; Martín-Belloso, O. Edible films from essential-oil-loaded nanoemulsions: Physicochemical characterization and antimicrobial properties. Food Hydrocoll. 2015, 47, 168-177. [CrossRef]

38. Ziani, K.; Fang, Y.; McClements, D.J. Fabrication and stability of colloidal delivery systems for flavor oils: Effect of composition and storage conditions. Food Res. Int. 2012, 46, 209-216. [CrossRef]

39. Donsì, F.; Ferrari, G. Essential oil nanoemulsions as antimicrobial agents in food. J. Biotechnol. 2016, 233, 106-120. [CrossRef]

40. Campolo, O.; Giunti, G.; Laigle, M.; Michel, T.; Palmeri, V. Essential oil-based nano-emulsions: Effect of different surfactants, sonication and plant species on physicochemical characteristics. Ind. Crops Prod. 2020, 157, 112935. [CrossRef]

41. Hashem, A.S.; Awadalla, S.S.; Zayed, G.M.; Maggi, F.; Benelli, G. Pimpinella anisum essential oil nanoemulsions against Tribolium castaneum-insecticidal activity and mode of action. Environ. Sci. Pollut. Res. 2018, 25, 18802-18812. [CrossRef]

42. Li, J.; Chang, J.W.; Saenger, M.; Deering, A. Thymol nanoemulsions formed via spontaneous emulsification: Physical and antimicrobial properties. Food Chem. 2017, 232, 191-197. [CrossRef] [PubMed]

43. Saberi, A.H.; Fang, Y.; McClements, D.J. Fabrication of vitamin E-enriched nanoemulsions: Factors affecting particle size using spontaneous emulsification. J. Colloid Interface Sci. 2013, 391, 95-102. [CrossRef]

44. Mirgorodskaya, A.B.; Kushnazarova, R.; Lukashenko, S.S.; Nikitin, E.N.; Sinyashin, K.O.; Nesterova, L.M.; Zakharova, L.Y. Carbamate-bearing surfactants as effective adjuvants promoted the penetration of the herbicide into the plant. Colloids Surfaces $A$ Physicochem. Eng. Asp. 2020, 586, 124252. [CrossRef]

45. Niedobová, J.; Skalský, M.; Ouředníčková, J.; Michalko, R.; Bartošková, A. Synergistic effects of glyphosate formulation herbicide and tank-mixing adjuvants on Pardosa spiders. Environ. Pollut. 2019, 249, 338-344. [CrossRef] [PubMed]

46. Moghimi, R.; Ghaderi, L.; Rafati, H.; Aliahmadi, A.; McClements, D.J. Superior antibacterial activity of nanoemulsion of Thymus daenensis essential oil against E. coli. Food Chem. 2016, 194, 410-415. [CrossRef] [PubMed]

47. Jesser, E.; Lorenzetti, A.S.; Yeguerman, C.; Murray, A.P.; Domini, C.; Werdin-González, J.O. Ultrasound assisted formation of essential oil nanoemulsions: Emerging alternative for Culex pipiens pipiens Say (Diptera: Culicidae) and Plodia interpunctella Hübner (Lepidoptera: Pyralidae) management. Ultrason. Sonochem. 2020, 61, 104832. [CrossRef] [PubMed]

48. Junkum, A.; Maleewong, W.; Saeung, A.; Champakaew, D.; Chansang, A.; Amornlerdpison, D.; Aldred, A.K.; Chaithong, U.; Jitpakdi, A.; Riyong, D.; et al. Ligusticum sinense Nanoemulsion Gel as Potential Repellent against Aedes aegypti, Anopheles minimus, and Culex quinquefasciatus (Diptera: Culicidae). Insects 2021, 12, 596. [CrossRef] [PubMed]

49. Mohammadi, R.; Khoobdel, M.; Talebi, A.A.; Negahban, M.; Norani, M.; Moradi, M.; Dehghan, O. In vivo Evaluation of the Repellency Effects of Nanoemulsion of Mentha piperita and Eucalyptus globulus Essential Oils against mosquitoes. Open Biotechnol. J. 2021, 14, 145-152. [CrossRef]

50. Sakulku, U.; Nuchuchua, O.; Uawongyart, N.; Puttipipatkhachorn, S.; Soottitantawat, A.; Ruktanonchai, U. Characterization and mosquito repellent activity of citronella oil nanoemulsion. Int. J. Pharm. 2009, 372, 105-111. [CrossRef]

51. Pavoni, L.; Pavela, R.; Cespi, M.; Bonacucina, G.; Maggi, F.; Zeni, V.; Canale, A.; Lucchi, A.; Bruschi, F.; Benelli, G. Green Microand Nanoemulsions for Managing Parasites, Vectors and Pests. Nanomaterials 2019, 9, 1285. [CrossRef] [PubMed]

52. Bougherra, H.H.; Bedini, S.; Flamini, G.; Cosci, F.; Belhamel, K.; Conti, B. Pistacia lentiscus essential oil has repellent effect against three major insect pests of pasta. Ind. Crops Prod. 2015, 63, 249-255. [CrossRef]

53. Giunti, G.; Campolo, O.; Laudani, F.; Zappalà, L.; Palmeri, V. Bioactivity of essential oil-based nano-biopesticides toward Rhyzopertha dominica (Coleoptera: Bostrichidae). Ind. Crops Prod. 2021, 162, 113257. [CrossRef]

54. Hori, M. Repellency of essential oils against the cigarette beetle, Lasioderma serricorne (Fabricius) (Coleoptera: Anobiidae). Appl. Entomol. Zool. 2003, 38, 467-473. [CrossRef]

55. Niogret, J.; Gill, M.A.; Espinoza, H.R.; Kendra, P.E.; Epsky, N.D. Attraction and electroantennogram responses of male Mediterranean fruit fly (Diptera: Tephritidae) to six plant essential oils. J. Entomol. Zool. Stud. 2017, 5, 958-964.

56. Arthur, F.H. Aerosol distribution and efficacy in a commercial food warehouse. Insect Sci. 2008, 15, 133-140. [CrossRef]

57. Lu, X.; Wang, C.; Zhao, M.; Wu, J.; Niu, Z.; Zhang, X.; Simal-Gandara, J.; Süntar, I.; Jafari, S.M.; Qiao, X.; et al. Improving the bioavailability and bioactivity of garlic bioactive compounds via nanotechnology. Crit. Rev. Food Sci. Nutr. 2021, 1-30. [CrossRef]

58. Price, D.N.; Berry, M.S. Comparison of effects of octopamine and insecticidal essential oils on activity in the nerve cord, foregut, and dorsal unpaired median neurons of cockroaches. J. Insect Physiol. 2006, 52, 309-319. [CrossRef]

59. Petrović, M.; Popović, A.; Kojić, D.; Šućur, J.; Bursić, V.; Aćimović, M.; Malenčić, Đ.; Stojanović, T.; Vuković, G. Assessment of toxicity and biochemical response of Tenebrio molitor and Tribolium confusum exposed to Carum carvi essential oil. Entomol. Gen. 2019, 38, 333-348. [CrossRef] 
60. Isman, M.B.; Grieneisen, M.L. Botanical insecticide research: Many publications, limited useful data. Trends Plant Sci. 2014, 19, 140-145. [CrossRef] [PubMed]

61. Scheff, D.S.; Campbell, J.F.; Arthur, F.H. Aerosol Dispersal Patterns and Resulting Effects on Tribolium confusum (Coleoptera: Tenebrionidae) Adults. J. Econ. Entomol. 2018, 111, 2435-2442. [CrossRef] [PubMed]

62. Toews, M.D.; Campbell, J.F.; Arthur, F.H. Temporal dynamics and response to fogging or fumigation of stored-product Coleoptera in a grain processing facility. J. Stored Prod. Res. 2006, 42, 480-498. [CrossRef] 